\title{
Sport specific policies and factors that influence international success: The case of tennis
}

\begin{abstract}
Countries continue to seek ways to achieve and sustain elite athlete success. However, competitive advantages in elite sport are largely found within individual sports' contexts and policies. This paper uses tennis as an exemplar and mixed methods to examine sport specific policy and other factors that influence international success. Thirty-five international tennis experts participated in a questionnaire which combined (a) open questions, and (b) Likert scale questions, based on the Sport Policy Factors that Lead to International Success (SPLISS) model. The findings support the significance of the SPLISS model at a tennis specific level. The most significant contribution of this paper rests on the emergence of two contextual themes, namely culture and commercial environment, which help explain the context within which tennis operates. These findings are important for understanding the ways elite sport success is fostered in professional sports like tennis and potentially transferring that knowledge to other commercialised sports. The paper advances the theoretical understanding of the combined meso-level and contextual factors at a sport specific level that influence international success. The practical implications address high performance directors' and sport policy makers' challenge of nurturing and enhancing the tennis culture and commercial environment.
\end{abstract}

Keywords: Tennis; elite sport policy; elite sport context; professionalisation; commercialisation; culture 


\section{Introduction}

Over the past two decades elite sport policy has received an increased research attention. Such research has offered advancements including an understanding of the common approaches and the key characteristics of elite sport systems of different countries (e.g., Andersen \& Ronglan, 2012; De Bosscher, De Knop, van Bottenburg, \& Shibli, 2006; Digel, Burk, \& Fahrner, 2006; Green \& Houlihan, 2005; Houlihan \& Green, 2008; Oakley \& Green, 2001). It is well documented (e.g., De Bosscher, De Knop, van Bottenburg, Shibli, \& Bingham, 2009; Robinson \& Minikin, 2012; Truyens, De Bosscher, Heyndels, \& Westerbeek, 2013) that countries and sports seek innovative ways to achieve and sustain elite success. On that note, several researchers called for research at sport specific level as elite sport development and sport competitive advantages are largely found within individual sports, their context and policies (e.g., De Bosscher, De Knop, \& van Bottenburg, 2007; De Bosscher, De Knop, van Bottenburg, et al., 2009; Sotiriadou \& Shilbury, 2009).

In that move away from country or sport generic studies and toward specific contexts, a few authors have further advanced the field of sport policies through studying certain aspects of the elite sport policy and key success factors of specific sports. These include the examples of Swedish athletics and Norwegian cross country skiing (Böhlke, 2007; Böhlke \& Robinson, 2009); Norwegian handball, Finnish ice hockey, Danish track cycling and Swedish tennis and golf (Andersen \& Ronglan, 2012); athletics (Truyens et al., 2013); and sprint canoe in Australia (Sotiriadou, Gowthorp, \& De Bosscher, 2013). Even though each of these studies had a different scope, they all identified new areas or important factors for success that were not addressed in sport generic studies. These studies illustrate the value of sport specific studies and their implications to high performance directors and policy makers.

Whilst sport policy studies and their influence on practice are flourishing, the relevance and influence of contextual factors, such as the professionalisation and 
commercialisation of some sports, and the role of the cultural, historical, political and social context to elite success is less prominent. Various studies (e.g., Andersen \& Ronglan, 2012; Bergsgard, Houlihan, Mansget, Nodland, \& Rommetveldt, 2007; Böhlke \& Robinson, 2009; Digel et al., 2006; Houlihan \& Green, 2008) showed that it is harder to analyse elite sport policy in isolation from contextual factors and these factors should be taken into account.

This paper addresses the need for sport specific research and the relevance of sportspecific contextual factors by examining the policy and other factors that influence international tennis success. Tennis is a sport where professionalisation and commercialisation have particularly increased over the past decades. However, the potential role of the professionalised and commercialised environment that tennis operates in is largely unknown. Consequently, tennis provides a valuable case for examination. The research question driving this study is 'What policy or other factors influence international tennis success?'. Using a mixed methods approach, a questionnaire comprised of open and Likert scale questions was used to collect data from 35 international tennis experts. This paper contributes to the body of research on elite sport policy and high performance management by responding to the need to examine elite sport policy at a sport specific level (De Bosscher et al., 2007; 2009). In addition, the findings allow for contextual factors that are important for international tennis success to emerge.

\section{Elite Sport Policies}

Studies that examined elite sport policies (i.e., factors at the meso-level) (e.g., Bergsgard et al., 2007; De Bosscher, De Knop, \& van Bottenburg, 2009; Digel et al., 2006; Green \& Houlihan, 2005; Houlihan \& Green, 2008; Oakley \& Green, 2001) conclude that the common characteristics of elite sport systems of developed nations are based around a single model of elite sports development with variations in the way elite sport policies are implemented. One of the most inclusive studies of meso-level factors that influence 
international sporting success that empirically tested a model in six nations, is the Sport Policy Factors that Lead to International Sporting Success (SPLISS) model (De Bosscher et al., 2006; 2009; De Bosscher, De Knop, van Bottenburg, et al., 2009). SPLISS identifies nine pillars (or policy areas) that influence international sporting success, and specifies 31 subdimensions and 126 critical success factors as key elements within pillars that are necessary to improve the elite sport success of a nation. Specifically, financial support (pillar 1) and an integrated approach to policy development (pillar 2) are necessary conditions for the development of sport and athletic careers within a given sport. Pillars 3, 4 and 5 represent the sequences of the athlete development stages including foundation and participation (pillar 3), talent identification and development (pillar 4) and athletic and post-career (pillar 5). Investment in four remaining pillars (i.e., pillar 6 training facilities, pillar 7 the provision and development of coaches, pillar 8 national and international competition structure and pillar 9 scientific research and sports medicine support) is essential for the development of elite athletes (De Bosscher et al., 2006).

Even though the focus of the SPLISS study was meso-level factors, the model suggests the inclusion of a tenth dimension; the environment of sport systems. This environment contains contextual factors such as the education system, the general sport and elite sport culture, the tradition of a certain sport in a country, the tradition of success, the private sector as a sports development partner, the media and sponsoring (Digel et al., 2006). However, the environment of sport systems was not examined in the SPLISS study, as it cannot be influenced directly by sports policies. Nevertheless, De Bosscher et al. (2007) recognised that policy and contextual factors need to be examined at a sport specific level. Based on this call, some studies examined elite sport policy at sport specific level (e.g., Andersen \& Ronglan, 2012; Böhlke, 2007; Böhlke \& Robinson, 2009; Green \& Houlihan, 2005; Sotiriadou et al., 2013; Truyens et al., 2013). Table 1a presents an overview of existing 
studies that include a sport specific level of analysis and shows their grounds for conducting sport specific research, the sports that were examined and the criteria for selecting these sports and countries. Furthermore, Table 1b shows the focus (including contextual factors), the methods and the frameworks used in previous studies.

\section{**** Table 1a and $1 \mathrm{~b}$ near here}

All studies presented in Table 1a, b examined elite sport policies by including some aspects of the context of elite sport (factors in italics in Table 1b). Even though each of these studies had a different focus, they all concluded that when comparing the factors that influence international sporting success, each sport requires the examination of its contextual factors. For example, Böhlke (2007) and Böhlke and Robinson (2009) compared athlete development pathways, coaching structures, sport science support and athletic lifestyle support in Swedish athletics and Norwegian cross country skiing to conclude that the implementation of these policies is strongly dependent on the socio-cultural context of a country. Therefore, policy makers have to take into account specific conditions such as the socio-cultural context, existing club competition infrastructures and working atmospheres in the sport environment, when attempting to transfer best practices across countries.

Sotiriadou et al. (2013) explored sprint canoe in Australia and identified that the sport's culture plays a key role in shaping policy, policy linkages and interrelationships. Truyens et al. (2013) examined the organisational resources (e.g., the existence of an organisation for the coordination and organisation of elite coach development) and first-order capabilities (e.g., a national coach qualification framework) that lead to a competitive advantage in athletics and classified these under the nine pillars of the SPLISS model. Also, an additional contextual category, called environmental success factors, emerged.

The sport examined in this study, tennis, is a highly globalised, professionalised and commercialised sport. These characteristics render tennis as an inviting case given previous 
empirical studies have not explored policy and contextual factors that influence international tennis success. The following section explains the structure and organisation of tennis at international level and illustrates its globalised, professionalised and commercialised nature.

\section{Study Context}

The International Tennis Federation (ITF) is responsible for developing and promoting tennis globally and regulates tennis through over 200 affiliated national tennis associations (ITFa, 2014). National Tennis Associations (NTAs) (e.g., Tennis Australia, the United States Tennis Association, and Tennis Canada) are the highest governing bodies in tennis at a national level, responsible for national tennis policies and programs. Professional tennis tournaments are controlled by the Association for Tennis Professionals (ATP) and the Women's Tennis Association (WTA). The foundation of these associations in the 1970s was a sign of professionalisation in tennis (Houlihan, 2013; Shilbury \& Kellett, 2011). Four of the most prestigious tennis competitions are the Grand Slam tournaments which are owned and organised by the NTAs of Australia, France, United Kingdom and the United States of America (ITFa, 2014). The worldwide competition structure of tennis and the increasing reputation of the sport in the Olympic Games (Fein, 2012) show the global nature of tennis. Tennis has the second highest global sport popularity after football (soccer), it is played in 190 countries, has 4.4 million fans and attracts 800 million television viewers worldwide (ATP, 2013a). Male tennis players including Roger Federer and Rafael Nadal are among the most recognisable athletes in the world (ATP, 2013a). In addition, the fact that the top 10 players on the women's tour represented 10 different countries in 2011 and the increasingly diversity of countries in the ATP and WTA top 100 illustrates the globalisation of tennis (Marshall, 2011).

As a consequence of its globalisation, tennis has become a commercialised sport featuring players as marketing commodities, huge broadcast rights and sponsors competing 
for exclusive rights to events (Churchill, 2008). Commercialisation has affected the way in which athletes relate to their sport with the most obvious impact being the increasing number of athletes who see tennis as a significant source of income (Houlihan \& Green, 2008). Tennis players can potentially earn a higher income from sponsorships then from their prize earnings. Houlihan (2013) argued that the commercialisation of high performance sport and the business of sport have impacted the relationship between players and their national governing bodies and International Federations. In tennis, the increasingly valuable sponsorship deals, prize money and the celebrity status of players have strengthened the power of players at the expense of NTAs and the ITF.

Even though NTAs play a major role in the development of elite tennis players, private high performance tennis academies, such as the Evert Tennis Academy and the IMG Nick Bolletieri Tennis Academy, are also important contributors to tennis success. Private tennis academies often strive for profit maximisation and complement (or sometimes undermine) the role of the NTA activities in talent identification and development programmes (Houlihan, 2013). The presence of these academies suggests that tennis players are not always ‘products’ of the formal system (i.e., the NTAs). There are several examples in the literature that illustrate the interplay between NTAs and private academies in producing elite athletes. A study in Flanders (the Northern part of Belgium), for instance, showed that tennis players training at an elite sport school have similar chances to become successful as those players training privately (De Bosscher \& De Croock, 2011). In Serbia there is no national tennis centre and most players develop privately or are offered sponsorships by companies (MacCurdy, 2008). Still, there are six Serbian players in the ATP/WTA top 100 ranking list (ATP, 2013b; WTA, 2013). Spain is one of the most successful tennis countries with 20 top 100 ATP/WTA players in the year-end ranking of 2013 (ATP, 2013b; WTA, 2013). In Spain, the number of players training at the national training centre is fairly low and 
there are a lot of players training in private tennis academies. However, nearly all players are under the umbrella of the NTA through grants, training camps and tournaments (MacCurdy, 2008). In general, Crespo and Reid (2009) indicated that NTAs and private academies need to cooperate as they strive for the same goal; developing elite tennis players.

To summarise, globalisation, professionalisation and commercialisation appear to have a great influence on NTAs' policies and should not be ignored when examining elite sport policy factors that influence international tennis success. This study examines such factors and policies in the context of tennis.

\section{Method}

\subsection{Data Collection}

An online questionnaire, designed using SurveyMonkey software, was used to collect data from international tennis experts including high performance directors, coach education managers and other tennis specialists. Drawing on experts’ opinion provides the best and most valid source of data (Bogner, Littig, \& Menz, 2009) to explore factors that influence international tennis success. The experts were selected from countries that are successful in tennis. Based on the number of male and female top 100 and 1000 players in the 2010 yearend rankings of the ATP and the WTA, 24 countries were chosen. Within these countries, two groups of tennis experts were selected using a purposive sampling process (Patton, 2002). The first group of experts included 25 high performance directors and 25 coach education managers from the NTAs of the 24 countries (with the exception of Belgium all other countries had one high performance director and one coach education manager). To increase the sample of participating experts, 25 more experts from the 24 countries were selected from the list of presenters at the bi-annually held Worldwide Coaches Conferences of the ITF between 2003 and 2011. This second group of experts included former high 
performance directors, elite coaches, science managers and researchers in tennis. This group is referred to as tennis specialists in the remainder of the paper.

Once ethics approval was granted from the institution authorising this research (Ethics project number RO1163), the web address link of the questionnaire was distributed by email to the tennis experts of the 24 selected countries. Email addresses of the experts were obtained through the websites of the NTAs or personal contacts. After eight weeks of distributing the questionnaire, two reminder emails and phone calls to countries where no response was obtained, a total of 35 experts from 15 countries completed the questionnaire (overall response rate $46.7 \%$ ). The highest response rate was received from tennis specialists (68,0\%). The response rate for high performance directors was 32.0\% and for coach education managers $40.0 \%$. More specifically, the experts included eight high performance directors (de-identified as HPD 1-8), 10 coach education managers (de-identified as CEM 110) and 17 tennis specialists (de-identified as Specialist 1-17).

\subsection{Description of Data}

A convergent parallel mixed methods design was used to collect and analyse the data (Creswell \& Plano Clark, 2011). This design allows for qualitative and quantitative data to be collected in parallel but analysed separately, and then mixed for the overall interpretation of the findings. This design was useful as this study is exploratory on one hand (tennis specific policies have never been examined) and explanatory on the other (the applicability of the SPLISS model for tennis is examined). The questionnaire used in the study included two sections. Open questions followed by Likert scale questions were used to collect both qualitative and quantitative data. Using open questions first in a questionnaire, followed by closed rating scale questions, is a recommended strategy in studies that examine the opinion of respondents (Brace, 2008; Reja, Manfreda, Hlebec, \& Vehovar, 2003). The convergent parallel design enabled this study to (a) examine the importance of the SPLISS pillars and 
sub-dimensions in tennis, (b) identify the extent to which the answers to the open questions overlap and reflect the SPLISS policies, and (c) explore if any new aspects, policies or tennis specific factors would emerge.

The first section of the questionnaire comprised three open questions. Specifically, tennis experts were asked to describe the five most important policy factors that contribute to international tennis success of countries in general (not the country they represented). Then the experts were asked to describe three strengths and three weaknesses of the policies in the country they represented. The open questions were used to (a) allow in-depth opinions on what the participants perceived to be important policies for tennis success and (b) explore additional factors that contribute or hinder international success by asking for strengths and weaknesses of the experts' countries. These questions allowed the experts to express their opinion without being influenced by a-priori defined SPLISS pillars and sub-dimensions.

In the second section of the questionnaire, the tennis experts were asked to rate on a 5-point Likert scale the importance of (a) the nine SPLISS pillars and (b) the 31 SPLISS subdimensions for international tennis success. For these questions, the pillars and subdimensions of the SPLISS model were tailored to reflect the tennis specific context. For example, pillar 3 ‘sport participation’ was converted into ‘tennis participation’. In the remainder of this paper, single quotation marks are used to indicate SPLISS sub-dimensions (e.g., 'high general tennis participation rate').

\subsection{Data Analysis}

The qualitative and quantitative data sets were analysed separately and independently from each other using qualitative and quantitative analytic procedures (Creswell \& Plano Clark, 2011). Within the qualitative data set, the three open questions were analysed independently in order to keep a clear distinction between factors that were mentioned as important and factors mentioned as strengths or weaknesses. Also, analysing answers 
separately allowed counting frequencies for each factor mentioned in each of the questions. Using NVivo10, the data from the three open questions were organised through paragraph styles and nodes for each of the three open questions for the independent analysis. Using NVivo10, three types of analyses were performed to assist with inductive and deductive reasoning (Grbich, 2013). These were (a) thematic analysis to code the responses under major themes, (b) constant comparisons to develop more specific sub-themes, and (c) content analysis to identify the percentage of experts that referred to each of the elite sport policies.

First, data were read and re-read in order to become familiar with what they entailed, concentrating on emerging patterns. During thematic analysis data were coded under the nine SPLISS a-priori policies in a deductive reasoning process. When a new factor or policy area emerged a new code was assigned and a description of what the new code meant was added (inductive reasoning). Subsequently, all quotations that were coded within each policy area or theme were re-read and through constantly comparing the quotations, data were coded under more specific $1^{\text {st }}$ and $2^{\text {nd }}$ level sub-themes until no further coding was possible (inductive reasoning). During content analysis, NVivo10 assisted in counting how many experts mentioned each theme and sub-theme as an important factor, a strength or a weakness. This process resulted in 11 themes, $441^{\text {st }}$ level sub-themes and $512^{\text {nd }}$ level sub-themes. The 11 themes are presented in italics in order to identify them easily.

The quantitative data from the Likert scale questions were analysed using rating averages (r.a.) ranging between one (not important) and five (very important). The standard deviation was calculated as an indication of the spread of the importance of the SPLISS pillars and sub-dimensions in tennis. Additionally, the standard error was calculated to examine whether rating averages were higher than the point of indifference (i.e., 3) with 95\% confidence. Last, the two sets of results were compared and combined into an overall discussion of the factors that influence tennis success (Creswell \& Plano Clark, 2011). 


\section{Results}

The results section starts with reporting the findings on the importance of the SPLISS pillars in tennis based on the thematic coding and content analysis of the open questions and the rating averages of the SPLISS pillars of the Likert scale questions. Then, the importance of the SPLISS sub-dimensions is presented based on the results of the Likert scale questions. This is followed by a discussion of the importance of each policy area and its sub-themes. Last, findings with regard to the contextual factors including culture and commercial environment are discussed.

\subsection{Important Policy Areas in Tennis}

Thematic coding and constant comparisons of data from the open resulted in 11 themes including nine policy related themes and two contextual themes. The nine policy related themes are the a-priori concepts of the SPLISS model including (1) financial support, (2) structure and organisation, (3) tennis participation, (4) talent identification and talent development, (5) athletic and post-career support, (6) training facilities, (7) coaching provision and coaches' education, (8) competition, and (9) scientific research. The new tennis specific contextual themes that emerged are (10) culture and (11) commercial environment of tennis.

Table 2 shows the results of the content analysis from the open questions and compares them with the rating averages for each pillar. Coaching provision and development was according to both sets of data analyses the most important policy area for tennis success, mentioned by 29 (82.9\%) tennis experts with a rating average of 4.83 (in bold in Table 2). This was followed by (inter)national competition, mentioned by 24 experts (68.6\%) with a rating average of 4.79 (in bold in Table 2). The low standard deviations (0.38 and 0.51 respectively) indicate a small variance in the tennis experts' responses. On the other hand, scientific research and athletic and post-career support were ranked in both data sets as the 
least important for tennis success (in italics in Table 2). Scientific research was mentioned by $14.3 \%$ with a rating average of 4.17 ) and athletic and post-career support was mentioned by $8.6 \%$ with a rating average of 4.14 ). The standard deviation for these pillars was 0.83 and 0.77 respectively, indicating that the answers of the experts were dispersed along the importance scale. Within pillar 5, 8.6\% of the experts referred to athletic career support and there was no reference to post-career support. The rating average of the SPLISS pillars based on the Likert scale questions (Table 2) revealed that all rating averages of the SPLISS pillars are greater than four. This indicates that all pillars are important for tennis success. Even though the sample size of this study is relatively small $(n=35)$, standard errors are low (ranging from 0.08 to 0.17 ) indicating that representativeness of the sample is high.

\section{**** Table 2 near here}

With regard to the contextual themes, $60 \%$ of the experts referred to culture and 25.7\% referred to the commercial environment of tennis (Table 2). Within the latter theme, $14.3 \%$ of the experts referred to the private sector, $8.6 \%$ referred to the media and $5.7 \%$ referred to sponsors as important factors for international tennis success.

\subsection{SPLISS Sub-dimensions and Sub-themes in Tennis}

After rating the importance of the SPLISS pillars in tennis, the experts rated the importance of the 31 pre-defined SPLISS sub-dimensions. These data added some additional depth to the nine pillars. In particular, the analysis showed that the rating averages of all subdimensions exceed the midpoint on the 5-point Likert scale (i.e., 3). Moreover, 25 of 31 subdimensions) have an average rating higher than four (Figure 1).

\section{**** Figure 1 near here $* * * *$}

Consistent with the analysis of the rating averages of the SPLISS pillars, the most important sub-dimensions related to coaching (pillar 7) and competitions (pillar 8). The high rating averages provide support that all SPLISS pillars and sub-dimensions are important in 
tennis. The rating averages of all sub-dimensions were more than two standard errors higher than the scale midpoint (i.e., 3) which indicates with 95\% confidence that the importance of the sub-dimensions is real and not by chance.

In order to present the results on tennis specific sport policy factors, the remainder of this section details the $1^{\text {st }}$ and $2^{\text {nd }}$ level sub-themes that emerged from the thematic analysis and constant comparison of the open questions. Table 3 is an overview of the nine policy themes and their $1^{\text {st }}$ and $2^{\text {nd }}$ level sub-themes. It shows that with regard to the financial support NTAs are responsible for attracting funding from governments, sponsors and tournaments to invest it toward mass participation and elite sport.

\section{**** Table 3 near here}

An interesting finding with regard to the structure and organisation of the NTA was that the experts' opinion on the suitability of a centralised or decentralised approach to elite development was polarised. Three experts indicated that decentralisation (i.e., strong regional training centres) is a policy strength, while four experts commented that the decentralisation of the NTA is a weakness.

The NTAs play an important role in the provision of pathways from mass participation to talent identification, talent development and the elite career of tennis players. In relation to tennis participation, NTAs are responsible for the development of a grassroots program, the promotion of tennis, tennis at school programs and the assurance of the quality of tennis clubs. Local tennis clubs are responsible for delivering quality programs and offering opportunities to play tennis at a low cost to increase the accessibility of tennis. Only two experts referred to the identification of talented players. In relation to talent development, the experts expressed the view that it is important to have, what Specialist 1 notes best, “collective training environments in which the best athletes train and push one another 
towards success" and "a school system which allows players to practice a lot with courses and exams adapted” (CEM 3).

Athletic and post-career support was the least frequently discussed policy in the open questions (Table 2). Athletic career support is concerned with the support for tennis players including training and coaching support, financial support and support at international competitions (Table 3). With regard to post-career support, a point for discussion among tennis experts related to the loss of expertise and experience of former elite players once they retired. HPD 5, for instance, mentioned that the small input of retired professional players to tennis was a weakness. Other experts indicated that former elite players may sometimes have a negative influence on the development of talented players. For example, HPD 1 found that "the influence of former players with a media profile that do not have the empirical evidence or developmental coaching experience” is a weakness.

Coaching and competitions appeared to be most important supporting policies for elite tennis success. Table 3 reveals that the availability of good quality and skilled coaches is very important. The experts referred to the importance of "top players becoming elite coaches after they finished their career” (Specialist 16), “the relationship between coaches” (CEM 8) and "support for local and regional coaches” (Specialist 11). In relation to coaches' education, experts saw value in "a clearly defined coaching philosophy” (Specialist 12) and “a coach development pathway” (Specialist 2).

With regard to competition, all three SPLISS sub-dimensions were in the top five of the highest rating averages (Figure 1). A good structure for both junior and senior competitions at national and international level is very important (Table 3), so that young talent and established players can compete regularly at an appropriate level. Furthermore, experts emphasised the importance of competitions played on different surfaces and the need for countries to organise international competitions in their country because it gives local 
players the opportunity to participate without having "to spend too much money to travel" (Specialist 15).

In relation to training facilities the experts referred to the availability and access to tennis courts. Also, experts indicated that NTAs should own a national training centre that serves as a collective training environment for young players. Finally, the experts referred to the importance of sharing the results of scientific research with the tennis community for better outcomes.

\subsection{Contextual Factors that Influence International Tennis Success}

Even though the experts were asked to mention policy factors in the open questions, more than half of the experts mentioned factors that are neither sport policies nor can be fully controlled by sport policies. These emerging factors are related to the culture and the commercial environment of tennis (Table 4). As these factors are not included in the SPLISS model, they are discussed separately in this section.

Sixty percent of the experts referred to culturally related factors that influence tennis success. Tennis culture was the most important $1^{\text {st }}$ level sub-theme and included the performances of elite players, the existence of tennis role models, the history of success in tennis and the cultural importance of tennis compared to other sports. For example, one expert highlighted the following:

[It is important] to have top players on the men's and the women's side that are capable of winning Grand Slam singles titles, Olympic gold medals and to have our tennis teams capable of winning the Davis Cup and the Fed Cup. It is of paramount importance to have positive role models for the young players to look up to and emulate. (Specialist 12)

Additionally, the overall sporting culture and the school culture emerged as important $1^{\text {st }}$ level sub-themes. With regard to the school culture, the experts referred to the limited time available for athletes to train during and after school hours and the lack of flexibility in the curriculum. A highly demanding school curriculum appeared to hinder the development of 
talented players in some countries. For example, CEM 3 mentioned that "the school system is not adapted to permit the players to practice as much as they should” and Specialist 3 indicated that "our school system is too demanding for talented players".

\section{**** Table 4 near here $* * * *$}

Nine experts (25.7\%) referred to the commercial environment of tennis, the second new theme that influences international tennis success. This relates to the $1^{\text {st }}$ level sub-themes private sector, media and sponsors. The private sector is concerned with the availability of high quality tennis clubs and their support programs for talented athletes (Table 4). This includes for example, “powerful tennis academies” (CEM 7), "tennis clubs running competitive junior programs and supporting competitive juniors" (Specialist 4) and "real tennis managers in the clubs” (HPD 7). Specialist 16 explains his view on the centralised or decentralised systems as follows:

[It is important to have] decentralised systems. Many high performance tennis academies and training centres run on a private basis throughout the country, not just one nationally ran program. [A centralised approach is] too narrow and cuts too many potential players out of the picture. Decentralised system adds a competitive atmosphere.

Based on the experts’ opinion, a good cooperation and communication between high performance academies and their NTA, and between clubs and NTA coaches is required to optimally support talented tennis players. For example, Specialist 3 mentioned the importance of "optimal collaboration between national training centres and private tennis projects for talents and elite players" and Specialist 2 stressed the need for "a clear and transparent pathway which offers athletes support across the entire developmental pathway with buy in from the private coach”. It should be noted that two experts also indicated negative points that related to the over-commercialisation of private high performance academies. For example, CEM 6 noted that "tennis schools are often favouring commercial elements above the quality of their development plans" and HPD 3 mentioned that "tennis 
clubs develop too much commercial activity to the detriment of the sporting activity of competition". However, Specialist 3 mentioned that "the budget of the private programs" should supplement the budget of the government and the NTA.

With regard to the $1^{\text {st }}$ level sub-themes of media and sponsors, experts referred to communication with the media, tennis exposure and promotion in the media. Some experts indicated that "a lack of media interest" (Specialist 13) and "a lack of promotion in the media” (CEM 10) are weaknesses in their country. Last, specialist 15 highlighted the importance of "a healthy federation from a financial point of view with excellent connections with sponsors and great communications with the media”.

\section{Discussion}

This study examined elite sport policies and other factors that influence international tennis success. The results provide support that the SPLISS model is applicable in tennis. However, based on the two grounds underlined below, the SPLISS model needs to be adapted in order to reflect the tennis specific context and therein lay the theoretical contributions of this study. The first ground for the adaptation of the SPLISS model relates to the emergence of two new contextual themes, culture and commercial environment. The second ground for modifying the SPLISS model is based on the relative importance that the tennis experts placed on specific policy areas of the SPLISS model in tennis. For example, competitions attracted high importance whereas post-career support emerged as relatively unimportant.

In addition to the encouraging findings toward a more inclusive empirical framework for analysing the factors that influence international success in tennis, this study also helps draw several practical implications for high performance directors and policy makers. These implications resonate deeply within the theoretical contributions of the study. The discussion section is built around the two grounds for adapting the SPLISS model to reflect the tennis specific context and offers practical implications to sport policy makers. 


\subsection{The Emergence of Culture and the Commercial Environment}

Culture and commercial environment emerged as new themes that are specific to tennis. Cultural factors include the school culture, the general sporting culture and the tennis specific culture. The latter refers to the history of success in tennis, the performance of elite players and the existence of tennis role models. The commercial environment includes the role of media, sponsors and the private sector. The role that media and sponsors can play for international tennis success is also confirmed in Andersen and Ronglan's (2012) and Wijk's (2012) findings who concluded that the exposure and promotion of tennis in the mass media and the existence of role models induced a wave of success in Swedish tennis in the 1980s. The example of Swedish tennis illustrates how the promotion and exposure of tennis in the media is closely linked to the popularity of tennis (i.e., tennis culture).

Also, with regard to the commercial environment, the findings showed that the private sector plays an important role in the development of elite athletes. However, it is quite possible that the private sector emerged as important because some of the tennis experts were (or may have been) active in the private sector during their careers. The results showed that the private sector in tennis offers highly professionalised training centres and high performance academies that are privately funded and offer complete athlete pathways from talent identification to elite level. There are many examples of successful tennis players that reached the ATP and WTA top 100 with no or little support from their NTA, including Rafael Nadal and David Ferrer. Examples of pathways outside the NTA that tennis players follow to become successful include training in high performance tennis academies, participating in American college tennis, having a parent serving as a coach, or private coaching through family funding (MacCurdy, 2008). Sometimes, players have individual coaching at little cost in return for a contract based on percentage of future earnings or players are offered private 
sponsorship or contracts by management or equipment companies (MacCurdy, 2008; Wijk, 2012).

The role of culture to sporting success is supported by two previous sport specific studies including a study on sport policies that lead to the success of canoe and kayak (Sotiriadou et al., 2013) and a study on the key resources for a competitive advantage in athletics (Truyens et al., 2013). The results in the present study support such findings and reiterate that the ways elite sport policies are shaped and implemented vary in order to reflect sport-specific cultures. The importance of the commercial environment to tennis success emerged due to the highly commercialised nature of tennis and its wide popularity as a sport (ATP, 2013a; Churchill, 2008). A large portion of NTAs’ income emanates from sponsorships and tournament revenues (e.g., Tennis Australia's income that is derived from organising and hosting the Australian Open). Therefore, NTAs might be less dependent on government funding than sports such as athletics, judo or swimming that are not as commercialised. Additionally, the tennis landscape has changed over the past 20 years. Private high performance academies exist in various countries (e.g., Spain, France, USA and Germany) and many elite tennis players use them as their training base (Brown, 2013; Idessane, 2011; Klemash, 2010). Therefore, this study supports that NTAs are not the sole organisations responsible for the development of elite tennis players, and that private high performance academies play also an essential role in the athlete development process. Consequently, it can be suggested that the importance of the private sector to elite athlete success may be similarly pivotal in sports like soccer and cycling where professional and commercial clubs (e.g., FC Barcelona in soccer and Cofidis in cycling) develop elite athletes.

Even though De Bosscher et al. (2006) excluded environmental factors (e.g., tradition of sport and success, the private sector, media and sponsors) from the SPLISS model as they cannot be influenced directly by sports policies, this study maintains that the culture and 
commercial environment should be considered when sport policy makers and managers examine factors that influence international tennis success. Taking into account that culture is a driver for sporting success, "it would be reasonable to nurture and strengthen it" (Sotiriadou et al., 2013, p. 17). Moreover, available strategic and high performance plans for tennis (e.g., Tennis Canada, 2013; Tennis New Zealand, 2013) make no reference to the culture or the commercial environment on player development and success. The study findings suggest that high performance directors and policy makers can no longer overlook these factors when planning or implementing elite sport policy and strategies in tennis.

NTAs, in collaboration with schools, can offer an integrated approach to achieving a balanced sporting career and quality education to further advance the culture of tennis (i.e., the demanding school culture). Therefore, the occasional agreements between sports and tertiary education institutions on class attendance flexibility and assessment benefits (e.g., De Knop et al., 1999; Nestel, 1992) should also prevail at primary and secondary schools. Further to this, in their efforts to promote the culture of tennis, NTAs can work closely with media outlets to broadcast tennis more on TV, increase newspaper obituaries on tennis, place tennis role models on the spotlight, and promote tennis programs at grassroots level.

Partnerships between public and private sectors are a prevalent practice (Bovaird, 2004) in various domains, such as public health (e.g., Reich, 2000). However, this concept is more contested in sports with an opportunity for NTAs to formulate policies that would enhance the contribution of the private sector and the commercial environment to tennis success. A stronger cooperation between NTAs and private high performance academies would offer flexible pathways for players to receive NTA support (e.g., trainings camps, competition support) and concurrently train in a private academy with a private coach. These flexible pathways would offer more players the opportunity to develop and succeed.

\subsection{Post-career Support in Tennis}


Even though all SPLISS pillars were recognised as important for international tennis success, the findings illustrate that the tennis experts value the role of some pillars more than others. The thematic analysis indicated that some of the SPLISS pillars were mentioned less frequently by the experts. Athletic and post-career support, for instance, was mentioned by only eight experts. This finding challenges the wide acceptance of post-career support that is advocated in various studies (e.g., Young, Pearce, Kane \& Pain, 2006; Stambulova, Stephan, \& Jäphag, 2007; Wylleman, Alfermann, \& Lavallee, 2004). However, this result can be explained on the basis that successful tennis players often earn more money through endorsement deals and sponsorships than they earn with prize money (Churchill, 2008). Such players can become financially independent and chose their own support team. Hence, the need for athletic and post-career support may be less prominent in tennis than in less commercialised sports such as judo or gymnastics (e.g., Wylleman et al., 2004). Another explanation for the low importance of post-career support could be that tennis experts are focused more on the success that athletes can achieve during their career and less on athletes' lives beyond their careers. Based on Martinkova and Parry (2011), it is common for some sports to be driven by extrinsic goals and for athletes to be used as instruments to achieve various values such as money, fame and success. The commercialisation of sport has led to the increasing commodification of athletes (Green \& Houlihan, 2008). Indeed, Connor (2009) argued that in commercialised environments elite athletes become interchangeable, are treated as business inputs and are exploited by high performance directors and coaches. In such business-like environments, it is likely that when athletes are injured or retire coaches and performance directors shift their support and focus to the next possible future elite athlete.

In a study on the retirement of 28 Australian female top 800 tennis players, Young et al. (2006) found that players would have benefited from the provision of a mentor, guidance 
or a sport psychologist, especially for lower ranked players who are not supported by the NTA. Research has shown that in order to give the best of their performance and to avoid and reduce adjustment problems after their sports career, athletes must start preparing during their sports career for life after sports (Stambulova et al., 2007; Wylleman et al., 2004). Therefore, post-career support could be a policy area that can be improved in many NTAs, or at the overall (national) sports level. Improved post-career support, such as the provision of a mentor or guidance by a sport psychologist (Young et al., 2006), will also decrease drop-out rates of talented tennis players, as their fear for a black hole after their tennis career will be less significant.

\subsection{Coaching and Competitions in Tennis}

The findings in this study show that the two most important policy areas for international tennis success are coaches' provision and education and (inter)national competition. While the SPLISS study has not yet validated the relative importance of the pillars, a small scale study in Flanders at sport generic level reported financial support, trainings facilities and coaches’ education as the three most important policy areas. Competition, the second most important policy area in tennis, was placed sixth of the nine pillars (De Bosscher \& De Croock, 2012). However, the findings in this study support the key role of competition on tennis success which is reflective of previous research that showed that a nation's provision of domestic, professional tournaments relates positively to that nation’s number of professionally ranked players (Crespo, Reid, Miley, \& Atienza, 2003;

Reid, Crespo, Santilli, Miley, \& Dimmock, 2007).

Competitions and coach education deserve to be prioritised in tennis elite development plans as they appeared the most important policy areas in tennis. It is also advised that NTAs provide coaches with a clear development pathway, a clear coaching philosophy, and clear communication channels between them and the NTAs. In addition, a 
strong certification system and opportunities for coaches to attend national and international coaching workshops would result in high calibre and well-respected coaches with strong core competencies. These recommendations are consistent with the requirements placed by the ITF for the recognition of NTA’s coach education systems (Crespo \& van de Braam, 2011; ITF, 2014b). Additionally, it is recommended that NTAs concentrate on attracting and hosting high quality international competitions within their countries. These competitions would provide upcoming players exposure without expecting them to travel in their search for ranking points (Crespo et al., 2003; Reid et al., 2007).

\section{Conclusion}

This study provides an overview of the policy areas and contextual factors that influence international tennis success. Even though the SPLISS model served as a suitable framework to examine policies at tennis specific level, the culture of tennis and its commercial environment need to be taken into consideration when examining factors that influence international tennis success. Additionally, a tennis specific model has to take into account that coaching and competition are more important policy areas in tennis than postcareer support and scientific research. The findings in this study confirm that the way elite sport policies are shaped and implemented vary in order to reflect sport specific needs (Sotiriadou et al., 2013; Truyens et al., 2013).

The tennis experts who participated in this study engage in a commercialised and professionalised high performance tennis system that constructs a particular set of presuppositions, beliefs and values. Therefore, it is likely that the sample of tennis experts might have influenced the findings of this study. From a social constructionist perspective, it is accepted that the environment within people live and the past experiences they engender drive the construction of their reality and the choices they make (Hutchison \& Charlesworth, 2011). Hence, it is not surprising that tennis experts rated the SPLISS policies as important. 
Also, the experts' entrenched frame of reference could help interpret their relative lack of support for post-career support and the importance they placed on the role of culture and commercial environment. Last, the high importance of coaching provision and education could be related to the fact that 10 of the participating tennis experts were coach education managers and 17 other experts were recruited from a coaches’ conference.

Even though the focus of this study was on policy factors, this study is among the first to highlight the importance of the private sector including private high performance tennis academies and their budgets, coaches, facilities and programs to develop elite tennis players. Therefore, the examination of the tennis policies of the NTA to explain tennis success may be insufficient without the inclusion of the private sector. Given that SPLISS is built on the premise that government funding and policies drive elite sport (De Bosscher, van Bottenburg, Shibli, \& De Knop, 2013), the emergence of the private sector in tennis draws attention to a potential weakness of the SPLISS study. The influence of the culture, media, sponsors and private sector on athlete development in tennis suggests that tennis operates in an open system where the sport maintains its internal differentiation and resists uniformity and homogeneity (Green \& Oakley, 2001; Houlihan \& Green, 2008; Pondy \& Mitroff, 1979). It is therefore recommended that future research builds on the preliminary findings of this study and adopts an open systems perspective which suggests that "organisations are open systems in that they influence and are influenced by the social, cultural, and economic conditions of the community in which they operate” (Chelladurai, 2009, pp. 73-74). Such research should expand beyond the policies of the NTAs and examine the contribution of all the potential actors (including private high performance academies) to elite tennis success. The proposed research would require the inclusion of performance directors and elite coaches of private tennis academies to examine their views on the ways the private sector contributes to elite tennis success. Also, further research is necessary to (a) examine the exact role that culture 
and commercial environment play in elite tennis success and (b) explore how NTAs can enhance the culture and enhance the role of the commercial environment to increase international tennis success. 


\section{References}

Andersen, S. S., \& Ronglan, L. T. (2012). Nordic elite sport: Same ambitions, different tracks. Copenhagen: Copenhagen Business School Press.

ATP. (2013a). 61 tournaments. 31 countries. 6 continents. 1 amazing opportunity. Beat this Retrieved 11 December, 2013, from http://www.atpworldtour.com/ /media/7D9146DF8B2B49A4916C697FE383F464.as hx

ATP. (2013b). ATP Rankings Retrieved 17 December, 2013, from http://www.atpworldtour.com/Rankings/Singles.aspx

Bazeley, P. (2007). Qualitative Data Analysis with NVivo. London: Sage Publications.

Bergsgard, N. A., Houlihan, B., Mansget, P., Nodland, S. I., \& Rommetveldt, H. (2007). Sport policy: A comparative analysis of stability and change. London: Elsevier. Bogner, A., Littig, B., \& Menz, W. (2009). Introduction: Expert interviews - An introduction to a new methodological debate. In A. Bogner, B. Littig \& W. Menz (Eds.), Interviewing experts (pp. 1-16). Hampshire: Palgrave Macmillan.

Böhlke, N. (2007). New insights in the nature of best practive in elite sport system management - examplified with the organisation of coaches education. New Studies in Athletics, 45(3), 49-59.

Böhlke, N., \& Robinson, L. (2009). Benchmarking of élite sport systems. Management Decision, 47(1), 67-84. doi: 10.1108/00251740910929704

Bovaird, T. (2004). Public-private partnerships: From contested concepts to prevalent practice. International Review of Administrative Sciences, 70(2), 199-215. doi: $10.1177 / 0020852304044250$

Brace, I. (2008). Questionnaire design: How to plan, structure and write survey material for effective market research. London: Kogan Page. 
Brown, O. (2013). How Wimbledon champion Andy Murray developed into a star at The Sánchez-Casal Academy Retrieved June 3, 2014, from http://www.telegraph.co.uk/sport/tennis/andymurray/10262898/How-Wimbledonchampion-Andy-Murray-developed-into-a-star-at-The-Sanchez-Casal-Academy.html

Chelladurai, P. (2009). Managing organisations for sport and physical activity: A systems perspective. Arizona: Holcomb Hathaway Publishers.

Churchill, G. (2008). The influence of commercialisation on the professionalisation of sport. Unknown.

Connor, J. (2009). The athlete as widget: how exploitation explains elite sport. Sport in Society, 12(10), 1369-1377. doi: 10.1080/17430430903204900

Crespo, M., \& Reid, M. (2009). Tennis powers and their keys to success. Paper presented at the ITF Coaches education programme: Coaching high performance players course, Location Unknown.

Crespo, M., Reid, M., Miley, D., \& Atienza, F. (2003). The relationship between professional tournament structure on the national level and success in men's professional tennis. Journal of Science and Medicine in Sport, 6(1), 3-13. doi: 10.1016/S14402440(03)80003-8

Crespo, M., \& van de Braam, M. (2011). The ITF recognition of coaches education systems of National Associations. ITF coaching \& sport science review, 54(19), 12-14.

Creswell, J. W., \& Plano Clark, V. L. (2011). Designing and Conducting Mixed Methods Research (2nd ed.). California, USA: Sage Publications.

De Bosscher, V., \& De Croock, S. (2011). The effectiveness of elite sport schools. A comparison of the career trajectory of elite athletes in Flanders, after attending or not attending an elite sport school. Paper presented at the 19th Conference of the European Association for Sport Management, Madrid, Spain. 
De Bosscher, V., \& De Croock, S. (2012). Trends in het Vlaams topsportklimaat, evaluatie volgens topsporters, trainers en topsportcoordinatoren: 2 meting (2003-2007-2011) [Trends in the Flemish elite sports climate, evulation according to elite athletes and high performance directors: 2-measurement (2003-2007-2011)]. Brussel: Vrije Universiteit Brussel.

De Bosscher, V., De Knop, P., \& van Bottenburg, M. (2007). Sports policy factors leading to international sporting success. Brussels: VUBPRESS.

De Bosscher, V., De Knop, P., \& van Bottenburg, M. (2009). An analysis of homogeneity and heterogeneity of elite sports systems in six nations. International Journal of Sports Marketing \& Sponsorship, 10(2), 111-131.

De Bosscher, V., De Knop, P., van Bottenburg, M., \& Shibli, S. (2006). A Conceptual Framework for Analysing Sports Policy Factors Leading to International Sporting Success. European Sport Management Quarterly, 6(2), 185-215. doi: $10.1080 / 16184740600955087$

De Bosscher, V., De Knop, P., van Bottenburg, M., Shibli, S., \& Bingham, J. (2009). Explaining international sporting success: An international comparison of elite sport systems and policies in six countries. Sport Management Review, 12(3), 113-136. doi: 10.1016/j.smr.2009.01.001

De Knop, P., wylleman, P., Van Hoecke, J., \& Bollaert, L. (1999). Sports management - A European approach to the management of the combitnation of academics and elitelevel sport. In S. Bailey (Ed.), Perspectives: The interdisciplinary series of Physical Education and Sport Science (Vol. 1, pp. 49-62). Oxford: Meyer \& Meyer.

Digel, H., Burk, V., \& Fahrner, M. (2006). High-performance sport. An international comparison (Vol. 9). Weilheim/Teck, Tubingen: Bräuer. 
Fein, P. (2012). How important is an Olympics Gold Medal? stevegtennis Retrieved 5 December, 2013, from http://www.stevegtennis.com/2012/07/how-important-is-anolympics-gold-medal/

Grbich, C. (2013). Qualitative data analysis: An introduction. London: Sage Publications.

Green, M., \& Oakley, B. (2001). Elite sport development systems and playing to win: Uniformity and diversity in international approaches. Leisure studies, 20(4), 247-267. doi: 10.1080/02614360110103598

Green, M., \& Houlihan, B. (2005). Elite sport development. Policy learning and political priorities. London and New York: Routledge.

Green, M., \& Houlihan, B. (2008). Conclusion. In B. Houlihan \& M. Green (Eds.), Comparative elite sport development: Systems, structures and public policy (pp. 272293). London: Butterworth-Heineman.

Houlihan, B. (2013). Commercial, political, social and cultural factors impacting on the management of high performance sport. In P. Sotiriadou \& V. De Bosscher (Eds.), Managing high performance sport (pp. 17-29). New York: Routledge.

Houlihan, B., \& Green, M. (2008). Comparative elite sport development. In B. Houlihan \& M. Green (Eds.), Comparative elite sport development: Systems, structures and public policy (pp. 1-25). London: Butterworth-Heineman.

Hutchison, E. D., \& Charlesworth, L. W. (2011). Theoretical perspectives on human behavior: Person and environment. In E. D. Hutchison (Ed.), Dimensions of human behavior (pp. 34-69). California: SAGE Publications

Idessane, K. (2011). Andy Murray's tennis school of good knocks Retrieved 4 June, 2014, from http://www.bbc.com/sport/0/tennis/13243702

ITF. (2014a). ITF Organisation, Role. Retrieved 6 February, 2014, from http://www.itftennis.com/about/organisation/role.aspx 
ITF. (2014b). Recognition of National Systems. Retrieved 6 February, 2014, from http://en.coaching.itftennis.com/coach-education/systems-recognition.aspx

Klemash, C. (2010). How to Succeed in the Game of Life: 34 Interviews with the World's Greatest Coaches: Andrews McMeel Publishing.

MacCurdy, D. (2008). A global look at top player development. ITF Coaching and Sport Science Review, 15(46), 27-29.

Marshall, A. (2011). Tennis' global evolution is bringing the sport to new markets: An analysis Retrieved October 11, 2013, from http://bleacherreport.com/articles/594875-the-global-evolution-of-tennis-is-bringingthe-sport-to-new-markets-an-analysis

Martinkova, I., \& Parry, J. (2011). The double instrumentality of sport. Studies in Physical Culture and Tourism, 18(1), 25-32.

Nestel, D. (1992). Athletic Scholarships: An Imbalance of Power Between the University and the Student-Athlete. Ohio State Law Journal, 53(5), 1401-1420.

Oakley, B., \& Green, M. (2001). The production of Olympic champions: International perspectives on elite sport development system. European Journal for Sport Management, 8, 83-105. doi: 10.1080/02614360110103598

Patton, M. Q. (2002). Qualitative research and evaluation methods (3rd ed.). Thousand Oaks, CA: Sage Publications.

Pondy, L. R., \& Mitroff, I. I. (1979). Beyond open system models of organization. Research in Organizational Behavior, 1(1), 3-39.

Reich, M. R. (2000). Public-private partnerships for public health. Nature medicine, 6(6), 617-620. doi: doi:10.1038/76176

Reid, M., Crespo, M., Santilli, L., Miley, D., \& Dimmock, J. (2007). The importance of the International Tennis Federation's junior boys' circuit in the development of 
professional tennis players. Journal of Sports Sciences, 25(6), 667-672. doi: $10.1080 / 02640410600811932$

Reja, U., Manfreda, L., Hlebec, C., \& Vehovar, V. (2003). Open-ended vs. close-ended questions in Web Questionnaires. Advances in methodology and statistics, 19, 159177. Retrieved from http://www.websm.org

Robinson, L., \& Minikin, B. (2012). Understanding the competitive advantage of National Olympic Committees. Managing Leisure, 17(2-3), 139-154. doi: 10.1080/13606719.2012.674391

Shilbury, D., \& Kellett, P. (2011). Sport management in Australia: An organisational overview. Crows Nest, Australia: Allen \& Unwin.

Sotiriadou, P., Gowthorp, L., \& De Bosscher, V. (2013). Elite sport culture and policy interrelationships: the case of Sprint Canoe in Australia. Leisure Studies, 1-20. doi: $10.1080 / 02614367.2013 .833973$

Sotiriadou, P., \& Shilbury, D. (2009). Australian elite athlete development: An organisational perspective. Sport Management Review, 12(3), 137-148. doi: 10.1016/j.smr.2009.01.002

Stambulova, N., Stephan, Y., \& Jäphag, U. (2007). Athletic retirement: A cross-national comparison of elite French and Swedish athletes. Psychology of Sport and Exercise, 8(1), 101-118. doi: http://dx.doi.org/10.1016/j.psychsport.2006.05.002

Tennis Canada. (2013). High performance handbook. Toronto, Ontario: Author. Retrieved March 13, 2014, from http://www.tenniscanada.com/files/hph2013.pdf

Tennis New Zealand. (2011). The Strategic Plan of Tennis New Zealand Inc. May 2011April 2014, Albany, Auckland: Author. Retrieved March 13, 2014, from http://www.tennisnz.com/Resource.aspx?ID=19343 
Truyens, J., De Bosscher, V., Heyndels, B., \& Westerbeek, H. (2013). A resource-based perspective on countries’ competitive advantage in elite athletics. International Journal of Sport Policy and Politics. doi: 10.1080/19406940.2013.839954

Wijk, J. (2012). The Swedish 'golf and tennis miracle' - two parallel stories. In S. S. Andersen \& L. T. Ronglan (Eds.), Nordic elite sport: Same ambitions, different tracks (pp. 109130). Copenhagen: Copenhagen Business School Press.

WTA. (2013). WTA Rankings Retrieved 21 December, 2013, from http://www.wtatennis.com/singles-rankings

Wylleman, P., Alfermann, D., \& Lavallee, D. (2004). Career transitions in sport: European perspectives. Psychology of Sport and Exercise, 5(1), 7-20. doi: 10.1016/S14690292(02)00049-3

Young, J. A., Pearce, A. J., Kane, R., \& Pain, M. (2006). Leaving the professional tennis circuit: Exploratory study of experiences and reactions from elite female athletes. British Journal of Sports Medicine, 40(5), 477-483. doi: 10.1136/bjsm.2005.023341 
Running Head: Elite sport policy

Table 1a. Sport policy studies at sport specific level: Reasons for the selection of sports and countries.

\begin{tabular}{|c|c|c|c|c|c|c|}
\hline & $\begin{array}{c}\text { Green and } \\
\text { Houlihan (2005) }\end{array}$ & $\begin{array}{l}\text { Digel et al. } \\
\text { (2006) }\end{array}$ & $\begin{array}{l}\text { Böhlke and Robinson } \\
\text { (2009); Böhlke (2007) }\end{array}$ & $\begin{array}{l}\text { Andersen and Ronglan } \\
\text { (2012) }\end{array}$ & $\begin{array}{l}\text { Sotiriadou et al. } \\
\text { (2013) }\end{array}$ & $\begin{array}{l}\text { Truyens et al. } \\
\text { (2013) }\end{array}$ \\
\hline $\begin{array}{l}\text { Reason for } \\
\text { sport specific } \\
\text { research }\end{array}$ & $\mathrm{n} / \mathrm{a}$ & $\mathrm{n} / \mathrm{a}$ & $\begin{array}{l}\text { Discipline specific } \\
\text { success of countries } \\
\text { Focus on success in } \\
\text { specific sports, rather } \\
\text { than across all sports }\end{array}$ & $\begin{array}{l}\text { Provide examples of } \\
\text { Nordic sports' sustained } \\
\text { success within a diversity } \\
\text { of sporting contexts }\end{array}$ & $\begin{array}{l}\text { It is essential to } \\
\text { discover what sport } \\
\text { specific factors } \\
\text { influence success } \\
\text { Examine the influence } \\
\text { of the environment of } \\
\text { sport systems on a } \\
\text { sport by sport basis }\end{array}$ & $\begin{array}{l}\text { Examine the } \\
\text { organisational } \\
\text { development in } \\
\text { specific sports } \\
\text { Call for sport specific } \\
\text { analysis (De Bosscher } \\
\text { et al., 2007; Oakley \& } \\
\text { Green, 2001) }\end{array}$ \\
\hline Sports & $\begin{array}{l}\text { Swimming } \\
\text { Athletics } \\
\text { Yachting }\end{array}$ & $\begin{array}{l}\text { Overall + } \\
\text { Athletics } \\
\text { Swimming } \\
\text { Volleyball }\end{array}$ & $\begin{array}{l}\text { Athletics } \\
\text { Cross-country skiing }\end{array}$ & $\begin{array}{l}\text { Overall + } \\
\text { Norway: Handball } \\
\text { Finland: Ice hockey } \\
\text { Denmark: Track cycling } \\
\text { Sweden: Tennis, Golf }\end{array}$ & Sprint Canoe & Athletics \\
\hline $\begin{array}{l}\text { Selection } \\
\text { criteria sport }\end{array}$ & $\mathrm{n} / \mathrm{a}$ & $\mathrm{n} / \mathrm{a}$ & $\begin{array}{l}\text { Successful sports and } \\
\text { elite sport systems in } \\
\text { Skandinavia }\end{array}$ & $\begin{array}{l}\text { Success stories of sport } \\
\text { Variety in sports (male - } \\
\text { female; individual - team } \\
\text { sports; summer - winter } \\
\text { sports) }\end{array}$ & $\begin{array}{l}\text { Medal winning sport } \\
\text { Tier } 1 \text { sport (funding) }\end{array}$ & $\begin{array}{l}\text { Rich history and } \\
\text { international } \\
\text { popularity among } \\
\text { international } \\
\text { competitors }\end{array}$ \\
\hline Countries & $\begin{array}{l}\text { Australia, } \\
\text { Canada, UK }\end{array}$ & $\begin{array}{l}\text { Australia, China, } \\
\text { France, Germany, } \\
\text { Italy, Russia, UK, } \\
\text { USA }\end{array}$ & $\begin{array}{l}\text { Sweden (Athletics) } \\
\text { Norway (Cross country } \\
\text { skiing) }\end{array}$ & $\begin{array}{l}\text { Nordic countries with } \\
\text { similar systems }\end{array}$ & Australia & 24 countries \\
\hline $\begin{array}{l}\text { Comparative } \\
\text { ambition }\end{array}$ & Yes & Yes & Benchmarking & Yes & No & No \\
\hline $\begin{array}{l}\text { Selection } \\
\text { criteria } \\
\text { countries }\end{array}$ & $\begin{array}{l}\text { English } \\
\text { speaking } \\
\text { countries }\end{array}$ & $\begin{array}{l}\text { Olympic tradition } \\
\text { Countries that } \\
\text { provide Olympic } \\
\text { sports with } \\
\text { privileged treatment } \\
\text { Governed on the } \\
\text { basis of ideological } \\
\text { concepts }\end{array}$ & $\begin{array}{l}\text { A democratic political } \\
\text { environment with a } \\
\text { stable economy }\end{array}$ & $\begin{array}{l}\text { Similar countries (size, } \\
\text { geographical region, } \\
\text { societal, political } \\
\text { institutions and welfare } \\
\text { state arrangements) } \\
\text { Lack of comparative elite } \\
\text { sport studies in Nordic } \\
\text { countries }\end{array}$ & $\begin{array}{l}\text { Top } 5 \text { Nation in sprint } \\
\text { canoe }\end{array}$ & $\mathrm{n} / \mathrm{a}$ \\
\hline
\end{tabular}


Running Head: Elite sport policy

Table 1b. Sport policy studies at sport specific level: Focus, methods and framework.

\begin{tabular}{|c|c|c|c|c|c|c|}
\hline & $\begin{array}{c}\text { Green and } \\
\text { Houlihan (2005) }\end{array}$ & $\begin{array}{c}\text { Digel et al. } \\
\text { (2006) }\end{array}$ & $\begin{array}{l}\text { Böhlke and Robinson } \\
\text { (2009); Böhlke (2007) }\end{array}$ & $\begin{array}{c}\text { Andersen and } \\
\text { Ronglan (2012) }\end{array}$ & $\begin{array}{l}\text { Sotiriadou et al. } \\
\text { (2013) }\end{array}$ & $\begin{array}{c}\text { Truyens et al. } \\
\text { (2013) }\end{array}$ \\
\hline $\begin{array}{l}\text { Focus } \\
\text { (Contextual } \\
\text { factors in } \\
\text { italics, } \\
\text { macro-level } \\
\text { factors } \\
\text { underlined) }\end{array}$ & $\begin{array}{l}\text { Elite facilities } \\
\text { Support for full } \\
\text { time athletes } \\
\text { Coaching, sport } \\
\text { science, medicine } \\
\text { support } \\
\text { Competition } \\
\text { opportunities }\end{array}$ & $\begin{array}{l}\text { Prioritisation } \\
\text { Sport participation } \\
\text { Organisational structure } \\
\text { Financial support } \\
\text { Talent search and } \\
\text { development } \\
\text { Coaches and education } \\
\text { Athletes, Referees } \\
\text { Training structures } \\
\text { Competitions, Facilities } \\
\text { Doping policy, Science } \\
\text { Education system } \\
\text { Mass media } \\
\text { Military force } \\
\text { History and Olympic } \\
\text { tradition } \\
\text { Social structure } \\
\text { Political system } \\
\text { Economic situation }\end{array}$ & $\begin{array}{l}\text { *4 elite sport services } \\
\text { 1. Athlete development } \\
\text { pathways } \\
\text { 2. Coaching structures, } \\
\text { education programmes } \\
\text { 3. Sport science support } \\
\text { 4. Athlete lifestyle } \\
\text { support } \\
\text { *5 interdependent factors } \\
\text { 1. Socio-cultural context } \\
\text { 2. Club competition } \\
\text { infrastructure } \\
\text { 3. Working atmosphere } \\
\text { in sports environment } \\
\text { 4. Personality and } \\
\text { knowledge of key agents } \\
\text { 5. Conscious } \\
\text { interventions }\end{array}$ & $\begin{array}{l}\text { Critical decisions } \\
\text { Controversies } \\
\text { Success stories } \\
\text { Policy issues } \\
\text { Systematic } \\
\text { comparisons } \\
\text { Success stories: } \\
\text { Development and } \\
\text { conditions for } \\
\text { breakthrough } \\
\text { Individual initiatives } \\
\text { and competencies } \\
\text { Ups and downs } \\
\text { Future prospects } \\
\text { Historical sport } \\
\text { developments (elite } \\
\text { vs. mass) } \\
\text { Organisational and } \\
\text { cultural conditions }\end{array}$ & $\begin{array}{l}\text { Coach } \\
\text { Athlete: pathways, } \\
\text { participation, } \\
\text { identification, talent } \\
\text { development } \\
\text { Organisation } \\
\text { Competition } \\
\text { Facilities and } \\
\text { equipment } \\
\text { Research and sport } \\
\text { science } \\
\text { Culture }\end{array}$ & $\begin{array}{l}\text { Financial support } \\
\text { Governance and } \\
\text { organisation of } \\
\text { policies } \\
\text { Youth participation } \\
\text { Talent identification } \\
\text { and development } \\
\text { Athletic career } \\
\text { support } \\
\text { Training and } \\
\text { competition facilities } \\
\text { Coach provision and } \\
\text { development } \\
\text { International } \\
\text { competition } \\
\text { Scientific research } \\
\text { Environmental } \\
\text { success factors }\end{array}$ \\
\hline Methods & $\begin{array}{l}\text { Descriptive and } \\
\text { comparative; } \\
\text { Interviews } \\
\text { Document } \\
\text { analysis }\end{array}$ & $\begin{array}{l}\text { Interviews } \\
\text { Analysis of literature } \\
\text { Socio-demographic } \\
\text { analysis of data } \\
\text { Analysis of documents } \\
\text { Questionnaires }\end{array}$ & $\begin{array}{l}\text { Semi-structured } \\
\text { interviews } \\
\text { Documentary analysis }\end{array}$ & $\begin{array}{l}\text { Specialists from each } \\
\text { nation } \\
\text { Variety of methods: } \\
\text { Historical material } \\
\text { Results statistics } \\
\text { Policy documents } \\
\text { Interviews }\end{array}$ & $\begin{array}{l}\text { Interviews with high } \\
\text { performance } \\
\text { directors, coaches, } \\
\text { sport scientists, } \\
\text { athletes }\end{array}$ & $\begin{array}{l}\text { Literature research } \\
\text { (sport overall and } \\
\text { athletics specific) } \\
34 \text { interviews with } \\
\text { athletics experts }\end{array}$ \\
\hline Framework & $\begin{array}{l}\text { Advocacy } \\
\text { coalition } \\
\text { framework (ACF) } \\
\text { to analyse policy } \\
\text { changes }\end{array}$ & $\begin{array}{l}\text { 1.Success-Resources- } \\
\text { model } \\
\text { 2. Neo-institutionalism } \\
\text { 3. Mintzberg's } \\
\text { organisation typology }\end{array}$ & $\begin{array}{l}\text { Benchmarking objects } \\
\text { and subjects } \\
\text { Elite support services }\end{array}$ & $\begin{array}{l}\text { Institutional } \\
\text { perspective } \\
\text { Relationship between } \\
\text { convergence and } \\
\text { divergence }\end{array}$ & $\begin{array}{l}\text { SPLISS model (De } \\
\text { Bosscher et al. 2006) } \\
\text { Contextual, } \\
\text { processual, specific } \\
\text { policies } \\
\text { (Houlihan, 2009) }\end{array}$ & $\begin{array}{l}\text { Recourse based view } \\
\text { Organisational } \\
\text { resources and first } \\
\text { order capabilities } \\
\text { clustered under the } \\
\text { SPLISS model }\end{array}$ \\
\hline
\end{tabular}


Running Head: Elite sport policy

Table 2. Ranking of importance of the SPLISS pillars based on Likert scale questions (rating average, standard deviation and standard error) and open questions (content analysis)

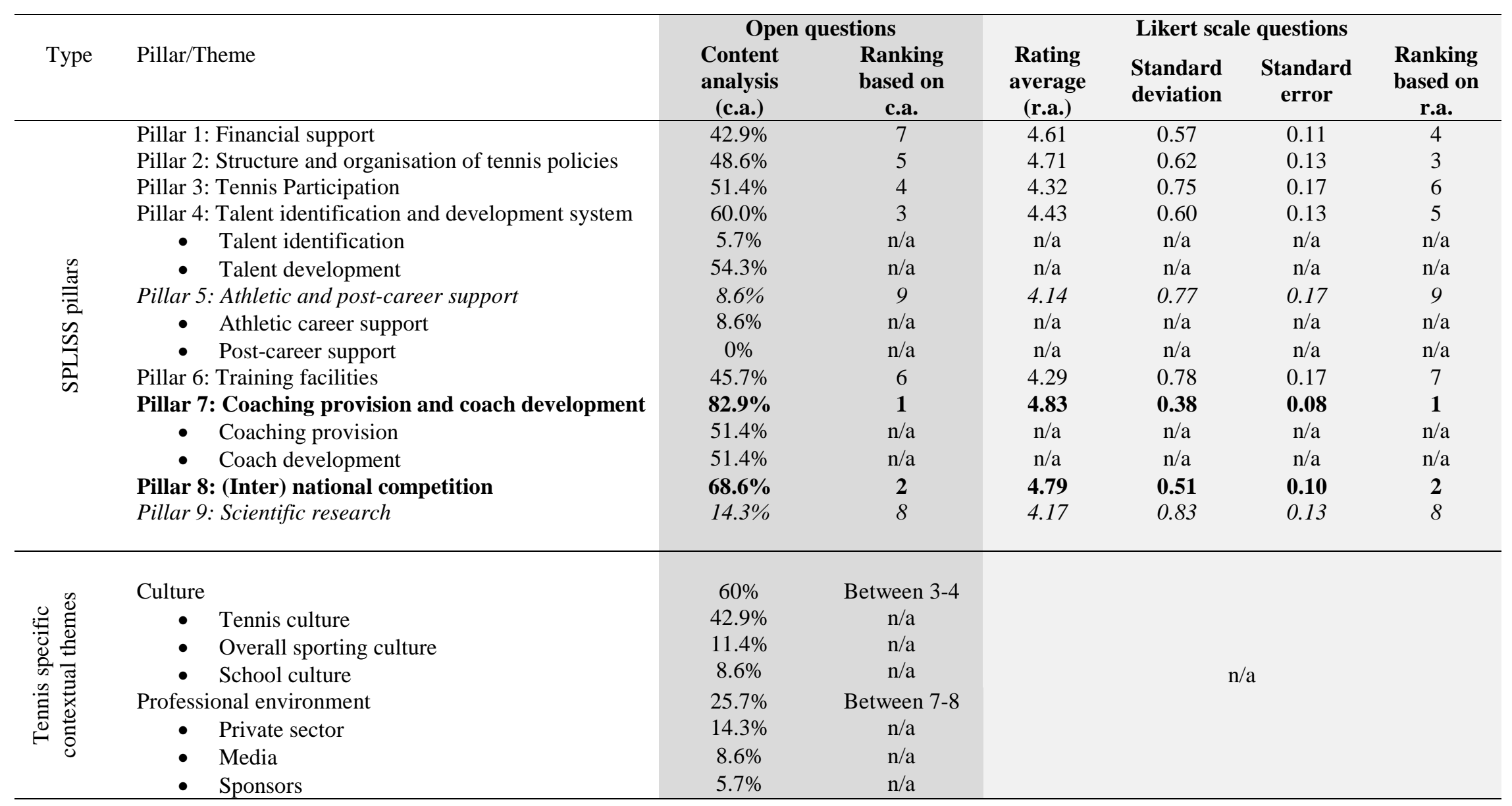


Table 3. Overview table of policy themes and sub-themes of factors that influence international tennis success.

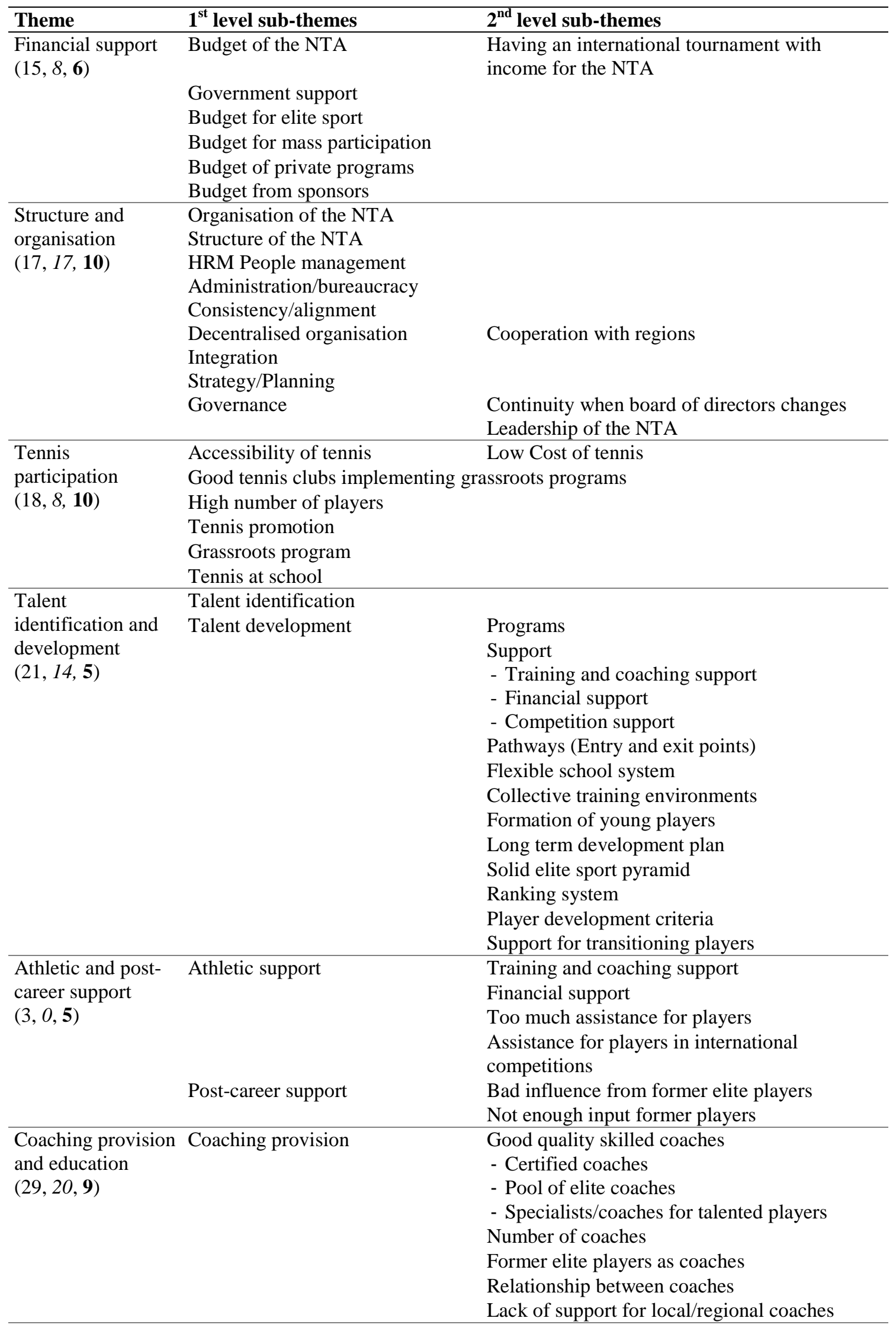


Running Head: Elite sport policy

\begin{tabular}{|c|c|c|}
\hline & Coaches education & $\begin{array}{l}\text { Clear coach philosophy } \\
\text { Clear pathway } \\
\text { Communication with coaches } \\
\text { Coaches workshops } \\
\text { Lack of strong certification }\end{array}$ \\
\hline \multirow[t]{2}{*}{$\begin{array}{l}\text { Competition } \\
(24,16, \mathbf{6})\end{array}$} & $\begin{array}{l}\text { Competition structure in own } \\
\text { country }\end{array}$ & $\begin{array}{l}\text { National competition } \\
\text { - Competition and tournaments at all levels } \\
\text { - Senior competition } \\
\text { - Junior competition } \\
\text { - Quality competition } \\
\text { - Quantity competition } \\
\text { - Team competitions } \\
\text { International competition } \\
\text { - Organisation international competition } \\
\text { - Quantity tournaments } \\
\text { - Quality tournaments } \\
\text { - Junior competition } \\
\text { - Senior competition } \\
\text { Competitions on all surfaces } \\
\text { Access to competition } \\
\text { Competitive environment }\end{array}$ \\
\hline & $\begin{array}{l}\text { Participation at international } \\
\text { competitions }\end{array}$ & Send best players to international competitions \\
\hline $\begin{array}{l}\text { Training facilities } \\
(16,4, \mathbf{6})\end{array}$ & $\begin{array}{l}\text { Availability (number of court } \\
\text { Access to facilities } \\
\text { A national training centre ow } \\
\text { Developed tennis academies } \\
\text { Low cost of training facilities } \\
\text { Availability of different surfa } \\
\text { Funds for renovation and buil }\end{array}$ & ities) \\
\hline $\begin{array}{l}\text { Scientific research } \\
(5,4,1)\end{array}$ & \multicolumn{2}{|c|}{$\begin{array}{l}\text { Know how } \\
\text { Player development criteria backed by research } \\
\text { Exchange with the rest of the world }\end{array}$} \\
\hline
\end{tabular}


Running Head: Elite sport policy

Table 4. Overview table of contextual themes and sub-themes that influence international tennis success.

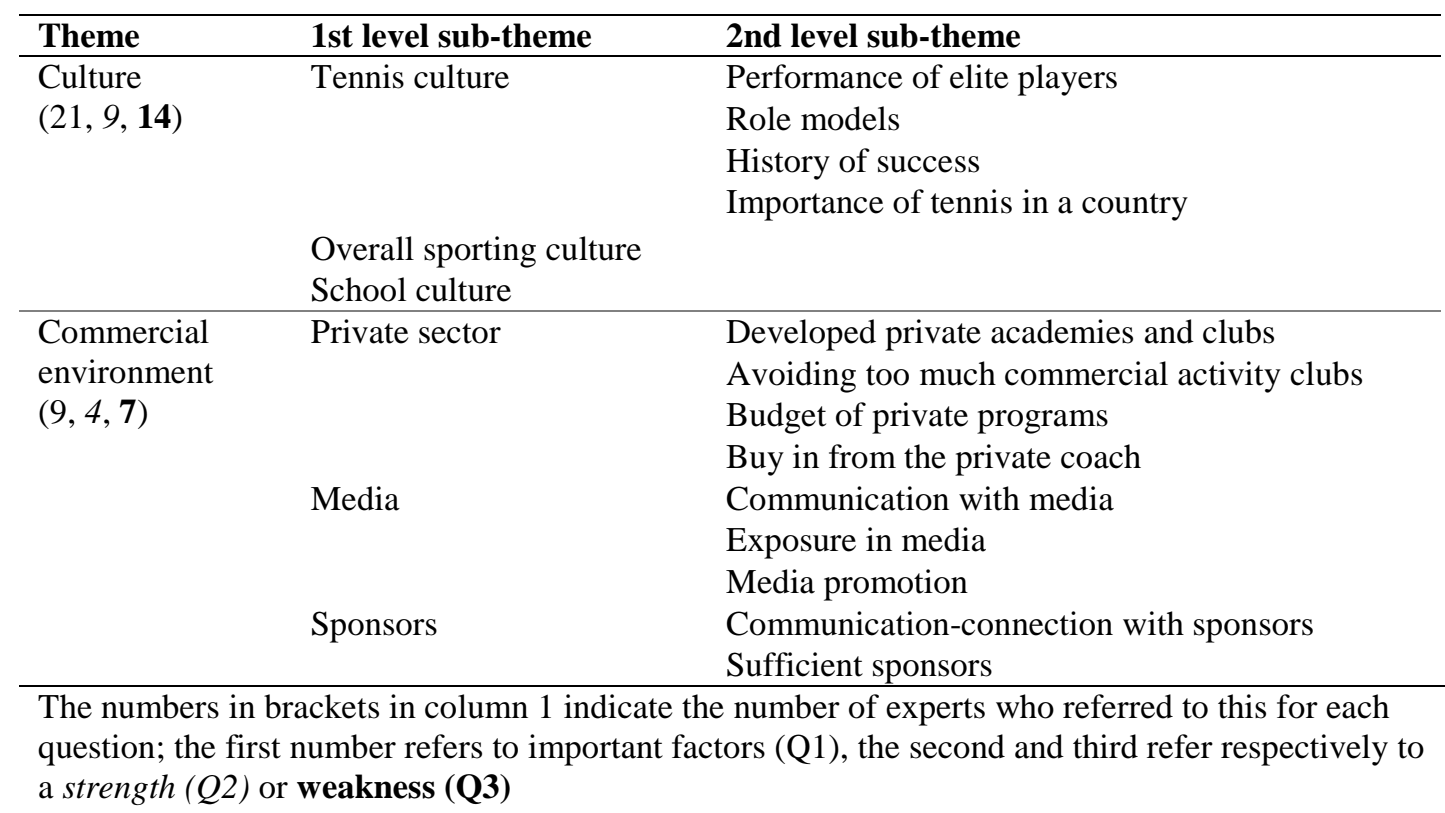


Figure 1. Rating average on the importance of 31 SPLISS sub-dimensions according to tennis experts $(n=35)$.

Enough well trained and experienced elite tennis coaches (P7) Good national tennis competition structure (P8)

Training and competition support for young tennis talents (P4)

National strategy for the organisation of international events (P8)

Opportunities to take part in international tennis competitions (P8)

Long term planning for elite tennis development (P2)

Network of high quality national/regional elite tennis centres (P6)

Multidimensional support programme for young talents (P4)

Sufficient financial support for the national tennis association (P1)

Sufficient financial support for grassroots tennis (P1)

Sufficient financial support for elite tennis (P1)

Coordinated planning for the development of talent in tennis (P4)

High general tennis participation rate (P3)

Opportunities for coaches to develop their training career (P7)

Effective system for the detection of young talent in tennis (P4)

Job of a tennis coach is recognised as valuable (P7)

A coordinated support program for elite tennis players (P5)

Career support (combination tennis and academic study) (P4)

National coordination plan for tennis facilities (P6)

Strong coordination of all agencies in elite tennis (P2)

The NTA and clubs can get funds for tennis facilities (P6)

Effective communication (P2)

Total quality management in tennis clubs is encouraged (P3)

Elite tennis is supported by scientific research at all levels (P9)

Participation in tennis at school (PE or extra curricular) (P3)

Good individual living circumstancesfor coaches (P7)

Good individual living circumstancesfor tennis players (P5)

Effective system to detect young talent (not sport specific) (P4)

Simplicity of administration (P2)

Own experience as a tennis player at high level (P7)

Post career support \& preparation for life after tennis career (P5)
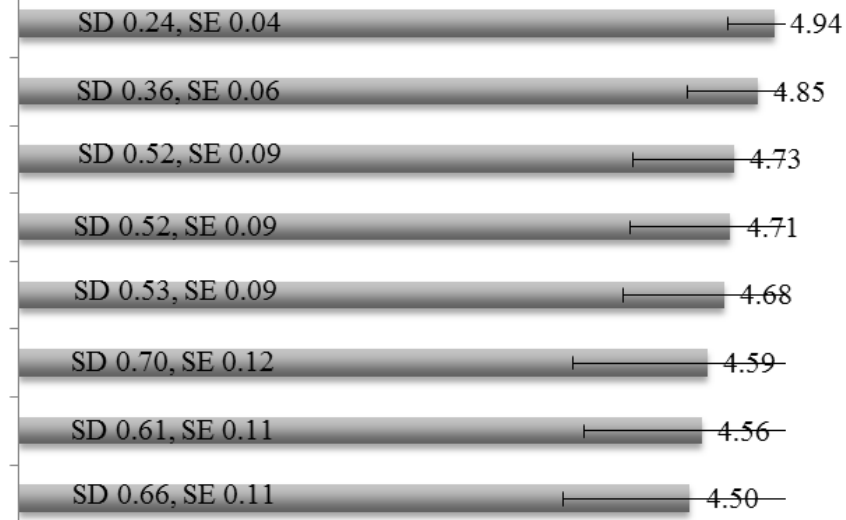

SD 0.68, SE 0.12

SD 0.75, SE 0.13

SD 0.76, SE 0.13

SD 0.84, SE 0.15

SD 0.82, SE 0.14

SD 0.70, SE 0.12

SD 0.77, SE 0.13

SD 0.73, SE $0.12 \quad \longmapsto 4.32$

SD 0.64, SE 0.11

SD 0.79, SE 0.14

SD 0.67 , SE $0.11 \quad \longmapsto$

SD 0.73, SE $0.13 \quad \longmapsto \quad+21$

SD 0.87, SE $0.15 \quad \longmapsto \quad+18$

SD 0.93,SE $0.16 \quad$

SD 0.70, SE $0.12 \quad \longmapsto \quad 4.15$

SD 0.77, SE 0.13

SD 1.13, SE 0.19

SD 0.81, SE $0.14 \quad \longmapsto \quad 3.94$

SD 0.95, SE $0.16 \longmapsto 3.88$

SD 0.96, SE $0.17 \quad \longmapsto \quad 3.74$

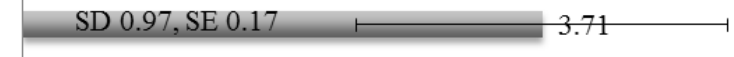

SD 0.79, SE $0.13 \quad \longmapsto \quad 3.56$

\begin{tabular}{ccccc}
\multicolumn{4}{c}{ SD 0.09, SE 0.16 } & \multicolumn{2}{l}{3.55} \\
\hline & 2.00 & 3.00 & 4.00 & 5.00
\end{tabular}

Rating Average

Note: The error bars indicate the standard deviation 